\title{
The Development of a Measure to Assess Perceptions of the Advanced Aircraft Training Climate
}

\author{
P. Naidoo, P. Schaap and L.P. Vermeulen \\ Department of Human Resource Management \\ University of Pretoria, Pretoria, Republic of South Africa.
}

Running head:

Advanced Aircraft Training Climate: Perceptual Measure

Training attitudes and airline pilots' specific learning experiences are ubiquitous antecedents, which impact human behavior on the flight deck. This paper reports on the development and psychometric evaluation of a scale to assess aviators' perceptions of the training environment associated with technologically complex aircraft. A sample of 229 airline pilots provided data to explore the latent structure of the hypothesized research construct. Principal axis factor analysis produced a three-factor model (Organizational Professionalism, Intrinsic Motivation, Individual Control of Training Outcomes) with highly acceptable Cronbach's alpha reliability coefficients.

A thorough knowledge of the environment associated with aircraft training is believed to have a significant impact on an organization's overall safety management system (Sexton \& Klinect, 2001). For instance, poor transfer of theoretical and/or synthetic learning may significantly impact an airline pilot's real-time judgement during mitigation of an adverse on-board situation (Ausink \& Marken, 2005; Casner, Geven \& Williams, 2012). As was the case reported by Wald (2009), when an Air France Airbus A330 crashed into the Atlantic Ocean after entering an area of severe icing conditions, which caused a malfunctioning of all primary and secondary flight control computers. In a separate, yet aerodynamically similar incident, a Turkish Boeing 737-800 impacted terrain on final approach after the pilots failed to monitor a defective automatic thrust control system (Kaminski-Morrow, 2009). Similar anecdotal occurrences over the past three decades have drawn observers' attention to the complexities of the advanced aircraft human-machine interface (Chambers \& Nagel, 1985; Poprawa, 2011; Sherman, 1997). Various scholarly studies and industry investigation have found that generally, as much as two-thirds of serious incidents and accidents in the technologically advanced aircraft were the result of human factor (HF) issues such as, a loss 
of situation awareness (perception, comprehension, projection) or situational control, automation complacency, poor decision-making, omission of action or inappropriate action, or flawed judgment (Bent, 1996; Boeing, 2009; Helmreich, 2002; Parasuraman, Sheridan \& Wickens, 2000; Poprawa, 2011; Sherman, 1997).

Although commercial air travel is regarded as possibly the safest mode of transportation available, it is expected that fatalities (although low) will continue into the future, as next generation commercial jet aircraft continue to dominate the skies (NTSB, 2009). Unprecedented technological improvements have resulted in greater efficiency and safety, so it appears likely that manufacturers will continue to pursue the continuing evolution of aircraft by designing increasingly advanced computer-based systems in the hope of orders from global airline companies (Baum, Gatchel, \& Schaeffer 1983; Boeing, 2009; Poprawa, 2011). However, the actual improvement of safety from a human factor perspective has been questioned by a number of experts in the field for some time now (Barker, 2011; Helmreich, 2002; Parasuraman \& Riley, 1997). The intricacy of complex systems (for example, automatic thrust levels, computer mode changes and so forth) in both normal and abnormal flight situations requires a new level of cognition from advanced aircraft pilots (Ausink \& Marken, 2005; Singh, Sharma, \& Singh, 2005). Human factor issues are significantly associated with airline pilots' perceptions. One study into the perceptions of advanced aircraft pilots has suggested that the level of learning and comprehension required in transition training was an important factor in individual mastery of safety-critical nuances of this type of aircraft (Naidoo, 2008).

In both of the accidents referred to at the start of this paper, the final accident investigation reports cited the pilots' confusion about some part of the technologically advanced automation system. In the Airbus accident, the pilots grossly underestimated the level of protection offered by technology and automation, resulting in a deep stall situation. In the Boeing 737-800 accident, the pilots were complacent in expecting the autopilot to perform normally in all situations, resulting in a low altitude stall. Such accidents simply highlight the added vigilance and cognitive effort required to operate a modern advanced aircraft, thus requiring a paradigm shift (at both an individual and 
organizational level) in flight training (Chambers \& Nagel, 1985; KaminskiMorrow, 2009; Naidoo, 2008).

It is clear within the literature that pilot training will always play a fundamental role in mitigating HF related issues (Ausink \& Marken, 2005; Bainbridge, 1983; Naidoo, 2008; Parasuraman \& Riley, 1997; Sherman, 1997; Walters, 2002). These studies describe links to flight training phenomena, but decades of study have not yet revealed the pedagogical reasons for pilots' behaving in a certain way on the advanced flight deck per se. Hence, this paper attempts to investigate the latent structure of such phenomena so as to provide more insight into advanced aircraft training.

An analysis of adverse operational events in an advanced aircraft often lead airline organizations to provide additional training to an offending airline pilot, in an attempt to remedy the problems on which the incident is blamed. For example, after a pilot unexpectedly veered off the runway during landing in an Airbus A340-200, the airline opted to provide the pilot with a number of flight simulator training sessions in order to prevent future occurrences (CAA, 2013). This appears to be the norm amongst airline organizations that subscribe to what is claimed to be a just, trust or non-punitive culture (ALPA$S A, 2011)$. At face value, such training methodology appears sound, as the offending pilot receives rehabilitation. However, according to Helmreich (2002) and Mitchell, Vermeulen, and Naidoo (2009), in many instances, the pilot is simply the last link in a systemic chain of critical events, and therefore this solution would not provide an explanation of root causes. Rehabilitation of experienced pilots may be a symptomatic solution to a deeper training issue.

Therefore in this paper, an exploration of the phenomena associated with the advanced aircraft training climate proposes that airlines may require more insight into understanding of their training schedules, culture and environment, which may necessitate targeted organizational shifts to align pilots at an earlier point in training with the instructional intentions and goals of the organization. To understand root causes, the present study focuses on operationalizing the latent structure of pilots' perceptions of the training environment associated with advanced aircraft.

To date, no prior scientific research about the advanced aircraft training climate per se has been published. Moreover, the authors found scant new 
information about the link between training, human factors and aircraft with complex technology. From other training perspectives not specifically associated with the aviation industry, the evolution of educational research has produced many inventories to measure and explain how students acquire, retain and apply knowledge (Biggs, 1987; Moon, 2004; Pololi \& Price, 2000; Schaap, 2000; Thorndike, 2007).

The main purpose of the present study was to examine the factorial validity and reliability of an instrument to assess airline pilots' perceptions of the training climate in the context of advanced automated aircraft involving a cross-organizational sample of airline pilots from South Africa. The remaining sections of this paper discuss the conceptualization of the advanced aircraft training climate and its subsequent measurement. The findings in this paper may be of particular interest to aviation psychologists, human factor specialists, aviation safety practitioners, and departments in airlines engaged in flight training.

\section{Advanced aircraft training and human factor issues}

Clearly defining the term aircraft automation is inherently problematic. It is difficult to differentiate absolutely between automatic control and manual control, because aircraft control is on a continuum of varying levels of functionality (Parasuraman \& Riley, 1997; Parasuraman, Sheridan, \& Wickens, 2000; Röttger, Bali, \& Manzey, 2009). This is why pilots' interactions with appropriate levels of automation rank high among the human factor concerns of advanced aircraft manufacturers, and also forms a core golden rule (Airbus, 2011). An appropriate level of automation is highly dependent on flight phase context. Notwithstanding these difficulties, in general, human factor researchers concur that aircraft automation can be described as replacing a human function, either manual or cognitive, with a machine function (Bainbridge, 1983; Poprawa, 2011; Röttger et al., 2009; Parasuraman et al., 2000; Sherman, 1997).

Developing the piloting skills necessary to safely handle technologically advanced aircraft is recognized as a key driver to flight operational success (Helmreich, 2002; Singh et al., 2005). Therefore, a number of airlines have adopted an integrated approach to training that incorporates basic flying skills 
(raw data exercises) with complex technology coupled to the human factor footprint, in other words encompassing and assessing core Crew Resource Management (CRM) principles (for example, South African Airways, 2007). Because the autopilot system and automation are closely linked to advanced technology, pilots are required to deal with advanced aircraft problems in real time using knowledge acquired during classroom and synthetic flight training. In an attempt to reduce the level of artificiality, training may take place in what is termed LOFT (Line Oriented Flight Training) scenarios. Training for human factor issues in automation, such as the proper use and understanding of the Flight Mode Annunciator (FMA), using appropriate levels of automation, mode awareness and combatting automation complacency, are addressed biannually by such airlines on advanced, zero-flight time synthetic training devices (aircraft flight simulators).

A limitation of the research within the present body of knowledge in the context of training, technology, advanced aircraft systems and automation, is that it has failed to address directly the training perceptions of candidates who have undergone the transition to advanced aircraft. Closely related studies however, have found that an aviator can become psychologically constrained if the trainee is technology-averse, concluding with a poor knowledge base and a resultant lack of systems comprehension (Kaminski-Morrow, 2009; Naidoo, 2008; Röttger et al., 2009). This implies that for some reason the individual fails to make the required psychological paradigm shift so that effective training and subsequent transfer of knowledge to actual line operations occurs. Moreover, a study of perception can lead the investigator to understand the overall psyche of a trainee (Fishbein \& Ajzen, 2001). De Jong (2010) nonetheless contends that apart from the psychological changes needed for successful learning which impacts psyche and overall behavior, trainees also require specific cognitive ability to process complex information. A person's capacity in respect of working memory can be limited if learning is substantially hampered when knowledge acquisition requires substantive capacity. For instance, comprehending technologically complex aircraft automation such as programming the flight management system of an Airbus A330 aircraft requires substantive know-how and cognitive ability (De Jong, 2010; Naidoo, 2008). To solve this problem, airline-training organizations 
could design instructional environments that optimise the use of trainee pilots' short-term memory capacity, and ameliorate cognitive overload. For example, in the case of programming a flight management system, a trainee pilot can make optimum use of a learning event if information about the system is provided theoretically and re-enforced practically, for instance, in a flight simulator using pre-defined chunks of knowledge with the guidance of an instructor.

It may be feasible to propose that a poor training climate would substantially contribute to failures in a trainee's ability to make the required psychological shift and could subsequently hamper cognitive processing resulting in less effective training.

\section{Airline pilot training}

Two types of initial or $a b$ initio training for airline pilots are commonly discussed in the literature: pilots have either civilian or military training backgrounds (Bainbridge, 1983; SACAA, 2011; Taylor \& Emanuel, 2000). Although military-style trained pilots receive less team-based or multi-crew training during their initial flight training, their exposure to a regimented and highly structured pedagogical learning environment has always made them appear attractive to modern airline organizations (Bent, 1996; Moore, Po, Lehrer \& Telfer, 2001). Pilots' first exposure to basic flight training can certainly influence their overall perception of automation training during transition courses at airline organizations many years later (Naidoo, 2008; Vermeulen, 2009).

Generally, airline organizations are responsible for training advanced aircraft pilots to make the transition onto new aircraft (Ausink \& Marken, 2005). This transition consists of three broad components of a multidimensional approach to training stratification: a theoretical learning part, a flight simulator training part and a route (or actual flying) part (SACAA, 2011; Telfer \& Moore, 1997). It appears that such a training approach can therefore impact learning by connecting theoretical knowledge to practical flying aspects at three levels of analysis: at a micro, meso or macro level. The micro level is individual, psychological, as a learner undertakes self-study of the theory. The meso level is a group level, in an instructional team or social 
context, where learners work together to achieve a common goal in the flight simulator. At the macro level, or organizational level, a check airman who represents the interests of management or the organization assesses an individual learner for application of knowledge en route.

Some research suggests that flight simulation is a critical aspect of an airline pilot's training (Pasztor, 2009). The aim of flight simulator training, particularly in the context of advanced aircraft pilot learning, ranges from full development of an aviator to actual skills acquisition. The main aim of the full flight simulator (FFS) is to instil the instructor's own philosophy in the student by reinforcing knowledge practically. Learning perception is influenced and subsequently governed by a student pilot's initial flying training experience (military or civilian), individual circumstances and environment, in addition to the competency goals set by both the student and flight instructor. FFSs or synthetic flight training devices, can provide pilots with a unique opportunity to experience an aircraft first hand using all their main sensory organs, thereby reinforcing so-called muscle-memory (Martinussen \& Hunter, 2010). Research suggests that only actual practice can improve human functioning, and in this case, an aviator's flying ability, by developing a long-term memory from working memory. According to De Jong (2010), this result is achieved from a planned repetition of sequences.

\section{Contextualizing the training climate}

Because the main construct, advanced aircraft training climate, was a novel one, it came as no surprise that there was no established definition within the present literature. Thus, in order to operationalize the research construct, defining the term consisted of inducting established theory from the industrial and organizational psychology literature base. Two separate climatic constructs, namely a psychological climate and an organizational climate can be differentiated (Chung, 1996; Denison, 1996). However, the concept of organizational culture has for some time been difficult to define, as there appears to be little agreement on the meaning of the term, on how the construct should be assessed, and to what extent theories from anthropology, sociology, social psychology, and organizational behaviour need to be incorporated into its description (Schein, 2004). Pragmatically, for the 
purposes of the current study, organizational culture is defined as the shared way members of an organization have learned to think, perceive, and behave in relation to organizational issues, tasks, and problems. For the purposes of the present study, the psychological climate refers to cognitive sense making of the organizational environment. Furthermore, in its application to the present study, climate refers to an advanced aircraft pilot's cognitive processing and psychological sense making of the advanced aircraft.

Because climate researchers are "generally less concerned with [social] evolution but more concerned with the impact that organisational systems have on groups and individuals" (Denison, 1996, p. 621), the present research fundamentally gauged perceptions of aviators who have engaged in training for the advanced aircraft as individuals and in groups, within airline organizations. Fishbein and Ajzen (2001) established that employees (and in the present case, advanced aircraft trainees) adopt unique behaviour based on a perception of the organizational climate. So for instance, a negative perception may lead to poor performance in training (Sexton \& Klinect, 2001).

In order to cover the defined training climate completely, the survey instrument captured perceptions in terms of a theoretical component (technical knowledge on the aircraft) and, secondly in terms of a practical component (flight simulator and route training).

The research construct was operationalized using a total of 17 critical measurement domains, encapsulated within three fundamental dimensions (person, group, organization). At the micro level of analysis derived from psychology (the person), the domains of learning for technology, motivation to train, personality, training stress, and training decision-making were included. At the meso level of analysis derived from sociology (the group), the domains of training group dynamics, intergroup training behaviour, simulator training teams training conflict, power and communication were included. Finally, at the macro level of analysis derived from anthropology (the organization), the domains of training culture, knowledge environment, structure, training policy training standards, training planning were included (Andrews \& Thurman, 2000; Biggs, 1987; Fishbein \& Ajzen, 2001; Katz \& Khan, 1966; Nunnally \& Bernstein, 1994; Schein, 2004; Telfer \& Moore, 1997). 


\section{METHOD}

\section{Measuring Instrument}

After a robust review of the literature, the hypothesized research construct was operationalized using the Advanced Aircraft Training Climate Questionnaire (AATC-Q).

The overall quality of the content of the AATC-Q was validated a priori using a panel of 17 subject matter experts (SMEs). To achieve this aim, Lawshe's (1975) content validity ratio (CVR) was computed for each proposed indicator. Of the 17 subject matter experts, 12 were current airline training instructors, three were seasoned academics specializing in the field of industrial psychology, one was both an airline instructor pilot and an academic, and one was a management pilot. The mean age of the panel was 54.23 years $(S D=7.64)$. The participants had a high degree of industry experience, with a mean of 30.65 years $(S D=10.82)$. The mean advanced aircraft instructional experience of the airline pilots was 3781 hours ( $S D=2024)$, indicating a very high level of training expertise in the aviation industry. Generally, a CVR value of 0.46 is required to obtain the necessary validity when using a group of 17 experts (Lawshe, 1975) however, a more conservative cut-off point of 0.49 was subsequently agreed upon for use in this study.

Based on the prior literature, a non-exhaustive list of 106 items was initially contemplated and then proposed to the subject matter experts. Of the 106 items, 64 were deemed not essential or necessary. Hence, $39.62 \%$ of the original item list generated by the researchers was retained. This provided a highly robust measure of the research construct. Moreover, favourable results from a Cochran $Q$ test indicated that there was no significant $(Q[16]=$ 201.3697; $p<0.01$ ) inter-rater bias. According to Karlsson (2008) and Landis and Koch (1977), Cochran's Q test is an appropriate measure to determine whether the marginal probability of a positive response (that is, 1) is unchanged across a panel of judges. This provided sufficient empirical evidence for the researchers to conclude that the cohort of 42 essential or endorsed statements retained for the final questionnaire was statistically important.

A seven-point Likert-type scale was used with each statement to assess 
the perceptions of respondents at an approximate interval level (Uebersax, 2006). For each statement in the scale, the respondents indicated the degree to which they disagreed or agreed with the item or statement (where: $1=$ strongly disagree, $7=$ strongly agree). Kristovics (2010) strongly recommends that researchers maintain a pool of unidirectional statements in scale development to ameliorate possible response bias; all statements were thus positively worded. Therefore, a high score indicated that a respondent held a positive perception of the main construct based on that item.

\section{Sampling Procedure}

A cross-sectional stratified sampling procedure was used to target a known population of 1500 advanced aircraft pilots employed by six major airline companies in South Africa. An electronic version of the questionnaire followed by the paper-based version was distributed in two consecutive rounds. A total of 229 usable responses representing $15.3 \%$ of the target population were obtained.

\section{Participants}

In general, the population was well represented. The majority of the participants in the sample frame $(48.7 \%)$ came from the airline organization that employs the largest number of advanced aircraft airline pilots in South Africa, namely the national carrier, South African Airways. Table 1 clearly shows that in terms of the general flight experience levels of the group, the sample was fairly well distributed, with the majority of respondents having extensive experience of over 5000 hours (Mean=9753; SD=6116) flying time. However, the dispersion of the participants in respect of flight experience was large - the majority of the sample had between 3000 and 16000 flight hours. The high standard deviation of this descriptor testifies to the varying experience levels and age of pilots found in the South African airline industry. 
TABLE 1

Participant Details

\begin{tabular}{lcc}
\hline Category & Frequency & Proportion \\
\hline Organization & & \\
\hline $\begin{array}{l}\text { South African Airways } \\
\text { (Large carrier) }\end{array}$ & 112 & $48.7 \%$ \\
$\begin{array}{l}\text { British Airways Comair } \\
\text { (Large carrier) }\end{array}$ & 23 & $10.0 \%$ \\
$\begin{array}{l}\text { South African Express } \\
\text { (Medium carrier) }\end{array}$ & 14 & $6.1 \%$ \\
$\begin{array}{l}\text { South African Airlink } \\
\text { (Medium carrier) }\end{array}$ & 34 & $14.8 \%$ \\
$\begin{array}{l}\text { Mango Airlines } \\
\text { (Small carrier) }\end{array}$ & 11 & $4.8 \%$ \\
$\begin{array}{l}\text { 1Time Airlines } \\
\text { (Small carrier) }\end{array}$ & 10 & $4.3 \%$ \\
Other & 25 & $10.9 \%$ \\
\hline
\end{tabular}

\section{Main Aircraft \\ Manufacturer}

\begin{tabular}{lll}
\hline Boeing & 57 & $24.9 \%$ \\
Airbus & 95 & $41.5 \%$ \\
Other & 77 & $33.6 \%$ \\
& & \\
\hline
\end{tabular}

\section{Flying Experience (hours)}

\begin{tabular}{lll}
\hline Below 2000 & 7 & $3.0 \%$ \\
$2001-5000$ & 58 & $25.3 \%$ \\
$5001-7000$ & 30 & $13.1 \%$ \\
$7001-10000$ & 39 & $17.0 \%$ \\
$10001-15000$ & 57 & $24.9 \%$ \\
Above 15000 & 38 & $16.6 \%$
\end{tabular}

A fair proportion of the respondents (41.5\%) were experienced in some of the most advanced commercial jet airline aircraft currently in operation globally, namely Airbus A319/A320/A330/A340 (the majority of the respondents) and 
Boeing 747-400/737-400/800.

\section{Statistical Procedures}

Exploratory method

A Principal Axis Factoring (PAF) was used to gain an in-depth understanding of the latent structure of the dataset.

Kaiser's criterion (Comrey \& Lee, 1992), the parallel method of Horn (1965) and scree-plots (Cattell, 1966) were used to determine the number of significant factors to retain. According to Zwick and Velicer (1986), Horn's (1965) method provides the most accurate estimate of the number of true factors in a complex dataset. Although each of the criteria was considered in the various phases of the analysis, Horn's parallel analysis (PA) was applied for the purposes of determining the number of non-trivial factors. A Monte Carlo method was used to simulate the appropriate mathematical permutations on a random data set using specialized SPSS syntax developed by O'Connor (2000). All factors from the real data with eigenvalues greater than the eigenvalues from the random data sets were considered for retention.

\section{Reliability analysis}

Cronbach's coefficient alpha and item discriminant analysis (Cortina, 1993) were used to provide a statistical value of how well the set of items measured the latent construct and to examine internal consistency.

\section{RESULTS}

\section{Exploratory Factor Analysis}

The 42 items of the initial version of the AATC-Q were inter-correlated and rotated to an oblique simple structure by means of a Principal Axis Factoring (PAF) method and the promax rotation (Kappa =4). The KaiserMeyer-Olkin (KMO) and Bartlett's test of sphericity (KMO=0.927; Chi-square $\mathrm{p}$ $<0.001)$ showed that the sample $(\mathrm{N}=229)$ was adequate for the purposes of factor analyses. Using Kaiser's (1961) criterion, seven factors with eigenvalues greater than unity were initially extracted, which accounted for $66.248 \%$ of the variance in the factor space. However, the factor solution was 
weakly determined showing an unclear structure due to items not loading sufficiently and numerous cross-loadings. A simple or clear structure was obtained by deleting items with loadings lower than 0.40 , or which were found to have a high cross loading on more than one factor (Welman \& Kruger, 1999). Items whose properties appeared extremely similar were also discarded, as recommended by Tabachnick and Fidell (2007), resulting in the deletion of numerous items. The final cohort consisted of 33 items in a clean matrix, which were then subjected to a second round of PAF with promax rotation and Kaiser Normalization. A maximum of four non-trivial (significant) factors was obtained which reasonably explained the variability of the main research construct using Kaiser's criterion and the robustly modified version of Horn's (1965) parallel analysis (Velicer, 1976) (see Figure 1).

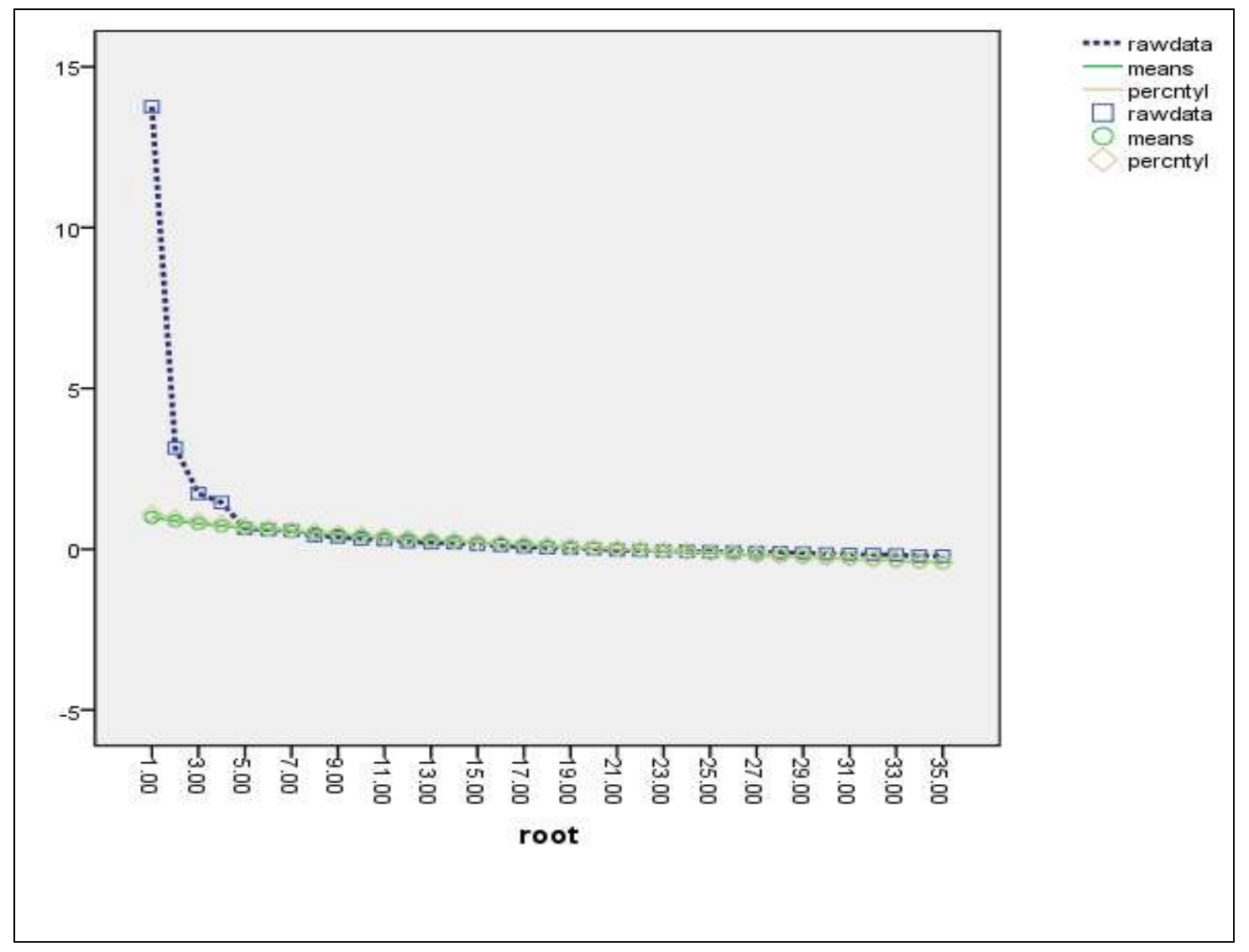

FIGURE 1: Parallel plot of the actual, mean and permutated eigenvalues.

The first four eigenvalues drawn from the actual data space of the 33-item AATC-Q was all above unity: 13.763, 3.152, 1.734 and 1.451. The 
eigenvalues from the actual data clearly exceeds the $95^{\text {th }}$ percentile eigenvalues $(1.11,0.96,0.88$ and 0.79$)$ permutated from random data which suggests that there were, at most, four non-trivial factors (statistically significant at $p<0.05)$. Parallel analysis only indicates the maximum possible number of factors to retain for a dataset; therefore theoretical considerations should serve to determine the actual number of meaningful factors (Hayton et al., 2004; O'Connor, 2000).

After closer inspection, it was determined that a four-factor solution was not clearly interpretable and meaningful. However, a three-factor model (Table 2) was meaningful from a theoretical perspective (Tabachnick \& Fidell, 2007). The high factor loadings (0.46 - 0.80) obtained on the factors were a clear indication that the variables were "pure" measures of the respective factors (Tabachnick \& Fidell, 2007, p. 649, Comrey \& Lee 1992, p. 203; Gorsuch, 1997; Zwick \& Velicer, 1986).

The computations presented in Table 3 reveal that the final three-factor solution explained $56.15 \%(40.301 \%+9.869 \%+5.978 \%)$ of the total variance in the data. According to Table 3, the three factors inter-correlated moderately with one another $(r=0.242$ to 0.446$)$. The strength of the correlations is small to moderate, indicating that the three factors are related, but can be considered independent constructs of perceptions of the advanced aircraft training climate (Leech, 2004; Tabachnick \& Fidell, 2007).

The factors were labelled according to the general content of related items with salient loadings, and consequently formed the measurement scales. The three factors describing the latent structure of pilots' perceptions of the advanced aircraft training climate were labelled Organizational Professionalism, Intrinsic Motivation and Individual Control of Training Outcomes. The three-factor finding supports the basic fundamentals of the organizational behaviour model based on the three levels of analysis, namely the macro, meso, and micro levels (Chung, 1996; Karlsson, 2008). The rationale and content of the factors can be explained as follows:

- $\quad$ Factor 1 (Organizational Professionalism)

This factor essentially relates to the formalized structural aspects of the training climate. Items from both the macro domain (the airline) and the 
TABLE 2

Factor Loadings and Corrected Item-total Correlations

\begin{tabular}{|c|c|c|c|c|c|}
\hline \multirow[t]{3}{*}{ Item } & \multirow[t]{3}{*}{ Statement } & \multirow{2}{*}{\multicolumn{3}{|c|}{ Factor Loading }} & \multirow{3}{*}{ 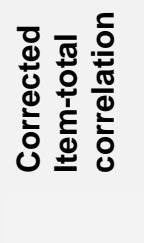 } \\
\hline & & & & & \\
\hline & & 1 & 2 & 3 & \\
\hline Q29 & Training on this aircraft is well organized. & 0.809 & -0.041 & -0.021 & 0.708 \\
\hline Q27 & Training on this aircraft is professional. & 0.808 & 0.082 & 0.015 & 0.767 \\
\hline Q23 & My company's training produces world class pilots. & 0.785 & 0.121 & -0.078 & 0.770 \\
\hline Q24 & Training at my airline is in line with company goals. & 0.785 & 0.115 & -0.057 & 0.725 \\
\hline Q38 & $\begin{array}{l}\text { The airline is very supportive of its pilots' learning requirements for } \\
\text { this aircraft. }\end{array}$ & 0.763 & -0.059 & 0.108 & 0.703 \\
\hline Q34 & There is sufficient training guidance from the company. & 0.762 & -0.143 & 0.109 & 0.667 \\
\hline Q28 & Management follows the rules and regulations appropriately. & 0.755 & -0.053 & -0.102 & 0.646 \\
\hline Q39 & My company's culture supports training for new technology aircraft. & 0.731 & -0.008 & -0.045 & 0.594 \\
\hline Q30 & I understand what the company expects of me when training. & 0.700 & 0.198 & 0.000 & 0.706 \\
\hline Q26 & My company has talented people in training. & 0.695 & 0.012 & 0.060 & 0.633 \\
\hline Q33 & $\begin{array}{l}\text { If I had to experience a problem in training, it's easy for me to } \\
\text { appeal. }\end{array}$ & 0.686 & -0.250 & 0.291 & 0.681 \\
\hline Q25 & I know what my company's training goals are. & 0.678 & -0.036 & 0.146 & 0.697 \\
\hline Q31 & Training at my airline produces safe pilots. & 0.644 & 0.217 & -0.043 & 0.670 \\
\hline Q40 & There is sufficient feedback about my training on this aircraft. & 0.606 & 0.029 & 0.090 & 0.546 \\
\hline Q42 & My company uses only current training material. & 0.589 & -0.106 & 0.035 & 0.428 \\
\hline Q41 & Training is in line with civil aviation regulations. & 0.586 & 0.281 & -0.078 & 0.595 \\
\hline Q32 & $\begin{array}{l}\text { The airline gives its pilots an appropriate amount of preparation } \\
\text { work for training. }\end{array}$ & 0.531 & -0.028 & 0.189 & 0.525 \\
\hline Q45 & My instructor is willing to listen. & 0.528 & -0.028 & 0.277 & 0.639 \\
\hline Q50 & Pilots are in direct control of the training outcome. & 0.522 & -0.111 & 0.397 & 0.696 \\
\hline Q36 & I'm given sufficient time to prepare for training on this aircraft. & 0.499 & 0.046 & 0.192 & 0.558 \\
\hline Q61 & It's a good idea to know more than what is required. & -0.341 & 0.759 & 0.340 & 0.689 \\
\hline Q52 & I try never to be late for a training session. & 0.208 & 0.746 & -0.257 & 0.828 \\
\hline Q53 & I co-operate when training in a simulator. & 0.209 & 0.745 & -0.238 & 0.810 \\
\hline Q62 & I aim to gain a deeper understanding of this aircraft. & -0.312 & 0.734 & 0.328 & 0.773 \\
\hline Q51 & Preparation improves performance. & 0.254 & 0.655 & -0.065 & 0.733 \\
\hline Q60 & $\begin{array}{l}\text { I read to understand so as to gain a deeper understanding of this } \\
\text { aircraft's systems. }\end{array}$ & -0.218 & 0.626 & 0.258 & 0.672 \\
\hline Q55 & I have a positive relationship with my colleagues. & 0.224 & 0.586 & -0.011 & 0.619 \\
\hline Q44 & I operate well as a crew member in the simulator. & 0.182 & 0.521 & 0.148 & 0.595 \\
\hline Q58 & I enjoy studying the technical aspects of the aircraft. & -0.089 & 0.493 & 0.316 & 0.594 \\
\hline Q63 & I'm comfortable undergoing training for this aircraft. & 0.182 & 0.130 & 0.594 & 0.601 \\
\hline Q57 & I'm in control of the outcome of a training session. & 0.326 & -0.017 & 0.529 & 0.656 \\
\hline Q64 & I can control my anxiety so as to perform well in training. & -0.073 & 0.103 & 0.523 & 0.497 \\
\hline Q49 & The instructors on this aircraft don't overload us with information. & 0.398 & -0.076 & 0.461 & 0.591 \\
\hline
\end{tabular}


TABLE 3

Factor Statistics of the AATC-Q

\begin{tabular}{|c|c|c|c|}
\hline Factors & 1 & 2 & 3 \\
\hline Eigenvalues & 14.105 & 3.454 & 2.092 \\
\hline Percentage Variance & 40.301 & 9.869 & 5.978 \\
\hline Squared Multiple Correlation (SMC) & 0.989 & 0.982 & 0.806 \\
\hline Factor inter-correlations & 1 & 2 & 3 \\
\hline 1. Organizational Professionalism & - & 0.446 & 0.431 \\
\hline 2. Intrinsic Motivation & 0.446 & - & 0.242 \\
\hline 3. Individual Control of Training & 0.431 & 0.242 & - \\
\hline Outcomes & & & \\
\hline
\end{tabular}

intermediate (instructor-trainee) domain loaded substantively onto Factor 1. The factor expresses a component of the theoretical construct in terms of the efficiency, effectiveness and professionalism of both the company and its flight instructors, aligning with the elements similar to the studies conducted by Biggs (1987), Moore et al. (2001), and Telfer and Moore (1997). The specific domains related to this factor were structure, training culture, training standards, training planning, knowledge environment, communication, and training policy.

- $\quad$ Factor 2 (Intrinsic Motivation)

This factor contains elements representing the micro level of analysis (the person). The factor predominantly reflects an individual trainee's ability and eagerness to learn and the ease of training associated with clear understanding, and comprehension of complex concepts relating to advanced aircraft. This dimension was in line with the findings of 
earlier studies into individual belief systems and subsequent motivation described by Fishbein and Ajzen (2001). The specific domains related to this factor were motivation to train, training decision-making, personality, training-related stress, and learning for technology.

- $\quad$ Factor 3 (Individual Control of Training Outcomes)

The third factor is evidence of an individual trainee's own perceived level of control in terms of stress levels and learning decision-making. Baum et al. (1983) found that adverse individual stress often leads to debilitating levels of anxiety, which in turn hamper effective learning. The essence of this third behavioural scale relates to the patterns of perceived comfort experienced by trainees during training, their belief in their ability to control the outcome of a training session, their capacity to control their levels of stress (eustress or anxiety) in order to perform well, and ultimately their grasp of the amount of information required to cope with their training (intelligent decision-making). Similar factors in other studies related the domains to students' perceived selfefficacy (Schaap, 2000). Elements of an individual control and training outcomes factor strongly relate to the extent to which learners experience success in any learning or training situation. Earlier studies by Zimmerman and Risemberg (1994), and by Tait and Entwistle (1996) claim that an individual's perception of environmental control is strongly associated with goal achievement and survival success. The specific domains of this factor were training stress and training decision-making.

\section{Reliability and item analysis}

The item discriminant analysis results reported in Table 2 revealed that the items contribute well to the overall measurement goal of each of the AATC-Q scales. The corrected item-total correlation of each item in the three factors was satisfactory at $r>0.20$. A significantly positive item-total correlation indicates that an item discriminates adequately between individuals with a high and low scale score (DeVellis, 2003).

The descriptive statistics and reliability coefficients for the scales are presented in Table 4. Reporting mean scale scores is useful to enable better comparisons across factors, specifically when there are different numbers of 
items per factor (Gorsuch, 1983; Green \& Salkind, 2008).

According to Table 4, the Cronbach alpha coefficients for the scales Organizational Professionalism ( $\alpha=0.952)$, Intrinsic Motivation $(\alpha=0.877$ ), and Individual Control of Training Outcomes $(\alpha=0.750)$ of the AATC-Q were satisfactory. The Cronbach's coefficient alphas $(\alpha)$ of all three scales were relatively high and exceeded the recommended threshold of 0.70 (Comrey \& Lee, 1992; Cortina, 1993; Cronbach, 1951; Morgan \& Griego, 1998; Nunnally \& Bernstein, 1994).

TABLE 4

Descriptive Statistics and Reliability $(n=229)$

\begin{tabular}{lccc}
\hline Descriptive & \multicolumn{3}{c}{ Behavioral Scale } \\
\cline { 2 - 4 } Statistics & Organizational & Intrinsic Motivation & Individual Control of \\
& Professionalism & & Training Outcomes
\end{tabular}

\begin{tabular}{llll}
\hline Mean & 5.791 & 6.301 & 5.742 \\
SD & 1.281 & 0.869 & 1.187 \\
Skewness & -1.241 & -1.392 & -1.328 \\
Kurtosis & 2.316 & 1.506 & 2.613 \\
r(Mean) & 0.663 & 0.632 & 0.558 \\
Alpha & 0.952 & 0.877 & 0.750
\end{tabular}

${ }^{*}$ mean item discrimination value

\section{SUMMARY AND DISCUSSION}

The primary purpose of the study was to develop a factorial valid and reliable instrument to assess airline pilots' perceptions of the advanced aircraft training climate.

A literature review on the topic of interest revealed that there are very few positivist measurement constructs available in the aviation industry, particularly in relation to the advanced aircraft airline industry. This gap in the research has resulted in much anecdotal evidence that is often mustered to support various human factor-related conclusions or claims. The flaw in this 
prior approach is that training organizations may then develop instructional system designs (ISDs) based on weak scientific evidence. Such an approach may aggravate airline companies' financial problems in the long term.

In this study, a theoretically and empirically substantiated three-factor measure to assess airline pilots' perceptions of the advanced aircraft training climate is presented which may be used to align training with the instructional intentions and goals of the organization.

There is strong theoretical support for the observed three-dimensional structure of the AATC-Q (Andrews \& Thurman, 2000; Biggs, 1987; Fishbein \& Ajzen, 2001; Katz \& Khan, 1966; Nunnally \& Bernstein, 1994; Schein, 2004; Telfer \& Moore, 1997). The factor pattern matrices revealed that two separate components were responsible for variability at an individual or person level of analysis and one component accounted for organizational imperatives. The three factors were subsequently labelled Organizational Professionalism, Intrinsic Motivation and Individual Control of Training Outcomes. The first factor relates to both the macro (organizational) and intermediate (instructortrainee) levels of analysis. Interestingly, the remaining two latent factors both entail variables related only to the micro or individual level of analysis. The correlation between Organizational Professionalism and the micro factors Intrinsic Motivation and Individual Control of Training Outcomes was moderate, but significant. The results suggest that variables related to the trainee (Intrinsic Motivation and Individual Control of Training Outcomes) play a clearly defined role in terms of the overall measure of perceptions of advanced aircraft training climate and also have a positive relationship with the perceived professionalism of both the company and its flight instructors (Organizational Professionalism). Therefore, an understanding of the individual factors that influence trainee's perceptions of the training climate could play an important role in the facilitation of effective learning by trainers. However, a trainee's understanding of the formalized structural elements that define the professionalism of training initiatives can be considered equally important in facilitating effective learning, and should therefore be managed appropriately through effective communication. This finding suggests that trainees may be considered a focal point in the phenomena associated with training for operating advanced aircraft (Fishbein \& Ajzen, 2001; Wickens, 
2000).

It can therefore be argued that it is vital for management and flight instructors to provide trainees with sufficient feedback and timeous learning plans to facilitate learning - Telfer and Moore (1997) argue that communication is a core element in the training environment of pilots. Effective communication based on effective feedback loops appears to be essential for creating a sustainable and highly favourable advanced aircraft training climate. The two-way communication feedback loop proposed within the advanced aircraft training climate should not be rigid or linear, but should involve a dynamic interaction between sender and receiver. The airline conducting the training should therefore explore various information-sharing methods, such as electronic versus paper-based communication. Conversely, sufficient feedback should also be encouraged from trainees. This would provide the evidence necessary for management to implement timeous changes, or to enhance training policies, procedures and structures systemically.

The prevalence of the micro-level subscale (Intrinsic Motivation and Individual Control of Training Outcomes) within the broader structure of the AATC-Q shows that the student is the cornerstone of any advanced aircraft training initiative. The domains highlight the individual pilot's role and ultimate responsibility for both the control over, and final success, of an advanced aircraft training event at a very personal level. Management and flight instructors should therefore provide sufficient support in the form of learning and study skill-sets to trainees who appear to be strong on the micro level and still seem to have problems. Instructors for advanced aircraft should therefore be extremely good empathizers, with an acute ability to understand others' motivations, perceived self-efficacy and stressors. Candidates who are not technologically averse, but who are unsuccessful, may simply not have, or may not be aware of, the tools available to them to facilitate their learning. In these outlier cases, one-on-one instructor-trainee input is required in order to strengthen the micro-dimension and thus enhance the training climate as perceived by that individual. The measures developed in this study make a quantitative and theoretical contribution to a better understanding of the advanced aircraft training climate from an interrelated three-dimensional 
perspective and can be effectively applied to promote a supportive training climate.

\section{Limitations}

An important limitation of the study stems from undetermined extraneous variables that could influence overall perceptions. These variables are related to the type of organization that provides the training and the leadership style associated with it, at both the managerial and instructional levels. Future research should therefore endeavour to select appropriate measures that incorporate elements that are relevant to specific contexts, and be cautious in generalizing the results of the AATC-Q to larger populations outside the South African context.

A cross-national comparison and validation using this measurement instrument could solve some of the problems related to the context-sensitivity of the three scales.

Although items to develop the scale were thoroughly researched and were based on previous studies of a similar nature in psychology and organizational behaviour, better items could arguably be selected, validated and found reliable in such measurement construction.

\section{Practical application and future research}

The statistical analysis of the AATC-Q's properties clearly shows that the measurement instrument displays an acceptable level of factorial validity and internal consistency of subscales. Hence practitioners, aviation human factor specialists, aviation psychologists, airlines and airline training organizations can use the instrument with reasonable confidence to gather valid and reliable data about the advanced aircraft training attitudes held by aircraft pilots in South Africa. Additionally, the scale can be used for organization comparison and longitudinal studies, as the three scales of the AATC-Q also demonstrate adequate power to discriminate between higher and lower scoring groups.

Evaluating the reliability and validity of scores from samples of pilots at foreign carriers would be useful. Moreover, such research may yield further 
data for a confirmatory factor analysis or structural equation modelling, which would provide a more rigorous test of the latent structure of the construct. Also, confirmatory multi-group models could be used to explore the degree of invariance of the factor structure across different countries and/or organizations.

It is recommended that contemporary airline organizations manage reliable and valid information appropriately by using appropriately validated scales.

The AATC-Q measurement instrument can provide the data required to convince management to address effectively any hazardous or flawed attitudes towards training for complex technology aircraft. Also, data collected from the instrument can easily be disseminated for discussion, in order to create an awareness of a pervasive training paradigm.

\section{ACKNOWLEDGEMENTS}

This study was part of a research project by Dr P. Naidoo, with supervision from Professor L.P. Vermeulen and Professor P. Schaap at the University of Pretoria, South Africa.

The authors declare that this manuscript has not been published elsewhere, nor has it been submitted simultaneously for publication elsewhere.

\section{REFERENCES}

Airbus. (2011). Flight crew operating manual, FCOM A330 Volume 1. Systems description. Toulouse: Airbus Training Centre.

ALPA-SA. (2011). Airline Pilots' Association of South Africa. Retrieved from http://www.alpa.co.za/ on 10 February 2011.

Ausink, J. A., \& Marken, R. S. (2005). Assessing the impact of future operations on trainer aircraft requirements. Santa Monica, CA: Rand.

Andrews, D. H., \& Thurman, R. A. (2000). An instructional systems development primer for aircrew training. In H.F. O'Neil, \& D. H. Andrews (Eds.), Aircrew training and assessment (pp. 110-152). New York, NY: Erlbaum.

Bainbridge, L. (1983). Ironies of automation. Automatica, 19(6), 775-779. 
Barker, D. (2011). Is aeronautical engineering getting too far ahead of itself? World Air News, April. Retrieved from http://www.airnews.co.za/ on 21 May 2011.

Baum, A., Gatchel, R. J., \& Schaeffer, M. A. (1983). Emotional, behavioural, and physiological effects of chronic stress at Three Mile Island. Journal of Consulting and Clinical Psychology, 51(4), 565-572.

Bent, J. (1996). Training for new technology. Hong Kong: Cathay Pacific Airways.

Boeing. (2009). Statistical summary of commercial jet airplane accidents, worldwide operations 1959-2009. Seattle, WA: Aviation Safety. Boeing Commercial Airplanes.

Biggs, J. B. (1987). Student approaches to learning and studying. Hawthorne: Australian Council for Educational Research.

CAA - See Civil Aviation Authority.

Casner, S. M., Geven, R. W., \& Williams, K. T. (2012). The effectiveness of airline pilot training for abnormal events. Journal of the Human Factors and Ergonomics Society, 20(3), 22-35.

Cattell, R. B. (1966). The scree test for the number of factors. Multivariate Behavioral Research, 1, 245-276.

Chambers, A. B., \& Nagel, D. C. (1985). Pilots of the future: Human or computer? Computer, 18(11), Nov, 74-87.

Chung, W. V. (1996). Ethnicity and organizational diversity: A study of social cognition and psychological climate perception. Lanham, MD: University Press of America.

Civil Aviation Authority (CAA). (2013). Accidents and incidents. Retrieved from http://www.caa.co.za/ on 11 May 2013.

Comrey, A. L., \& Lee, H. B. (1992). A first course in factor analysis. $2^{\text {nd }}$ ed. Hillside, NJ: Erlbaum.

Cooper, D. R., \& Schindler, P. S. (2003). Business research methods. $8^{\text {th }}$ ed. New York, NY: McGraw-Hill/Irwin.

Cortina, J. M. (1993). What is coefficient alpha? An examination of theory and applications. Journal of Applied Psychology, 78(1), 98-104. 
Cronbach, L. J. (1951). Coefficient alpha and the internal structure of tests. Psychometrika, 16(3), 297-334.

De Jong, T. (2010). Cognitive load theory, educational research, and instructional design: Some food for thought. Instructional Science, 38,105-134

Denison, D. R. (1996). What is the difference between organizational culture and organizational climate? A native's point of view on a decade of paradigm wars. Academy of Management Review, 21(3), 619-654.

DeVellis, R. F. (2003). Scale development: Theory and applications. Newbury Park, CA: Sage.

Fishbein, M., \& Ajzen, I. (2001). Belief, attitude, intention and behaviour: An introduction to theory and research. Reading, MA: Addison-Wesley.

Gorsuch, R. L. (1983). Factor analysis. Hillsdale, NJ: Erlbaum.

Gorsuch, R.L. (1997). Exploratory factor analysis: Its role in item analysis. Journal of Personality Assessment, 68(3), 532-560.

Green, S. B., \& Salkind, N. J. (2008). Using SPSS for Window and Macintosh: Analyzing and understanding data. $5^{\text {th }}$ ed. Upper Saddle River, NJ: Pearson Prentice Hall.

Hayton, J. C., Allen, D. G., \& Scarpello, V. (2004). Factor retention decisions in exploratory factor analysis: A tutorial on parallel analysis. Organizational Research Methods, 7(2), 191-205.

Helmreich, R. L. (2002). Managing threat and error in aviation and medicine. In: Proceedings of the Third LOSA Week (ICAO):15-22. Dubai, United Arab Emirates, October 14-16.

Horn, J. L. (1965). A rationale and test for the number of factors in factor analysis. Psychometrika, 30(2), 179-185.

Kaiser, H. F. (1961). A note on Guttman's lower bound for the number of common factors. British Journal of Statistical Psychology, 14(1), 1-20.

Kaminski-Morrow, D. (2009). Nine killed as Turkish 737 breaks up during Amsterdam landing. Flight Global, 25 February. Retrieved from http://www.flightglobal.com/ on 22 March 2009. 
Katz, D., \& Khan, R. L. (1966). The social psychology of organizations. New York, NY, \& London: Wiley.

Karlsson, C. (2008). Researching operations management. New York, NY: Taylor and Francis.

Kristovics, A. (A.kristovics@uws.edu.au) (2010). Balanced item pool. [E-mail to:] Vermeulen, L. P. (Ivermeul@tiscali.co.za) 30 March 2010.

Landis, J. R., \& Koch, G. G. (1977). The measurement of observer agreement for categorical data. Biometrics, 33(1), 159-174. Retrieved from: http://www.jstor.org.innopac.up.ac.za/ on 10 July 2009.

Lawshe, C. H. (1975). A quantitative approach to content validity. Personnel Psychology, 28, 563-575.

Leech, N. L. (2004). Enhancing the interpretation of "significant" findings: The role of mixed-methods research. Qualitative Report, 9(4), 760-810.

Martinussen, M., \& Hunter, D. (2010). Aviation psychology and human factors. Boca Raton, FL: CRC.

Mitchell, J., Vermeulen, L. P., \& Naidoo, P. (2009). Flying glass: A qualitative analysis of pilot perceptions of automated flight-decks after 20 years. International Journal of Applied Aviation Studies, 9(1), 13-29.

Moon, J. A. (2004). A handbook of reflective and experiential learning. Theory and practice. New York, NY: Routledge/Falmer.

Moore, P. J., Po, T., Lehrer, H. R., \& Telfer, R. A. (2001). Quality training and learning in aviation: Problems of alignment. Journal of Air Transportation Worldwide, 6(1), 56-75.

Morgan, A. G., \& Griego, O. V. (1998). Easy use and interpretation of SPSS for Windows: Answering research questions with statistics. London: Erlbaum.

Naidoo, P. (2008). Airline pilots' perceptions of advanced flight deck automation. Unpublished Master's thesis, University of Pretoria, Pretoria, South Africa.

National Transportation Safety Board (NTSB). (2004). Aircraft accident report: Flight separation of vertical stabilizer American Airlines flight 587 Airbus Industrie A300-605R, N14053 Belle Harbor, New York November 12, 2001. Washington, DC: NTSB. 
NTSB - see National Transportation Safety Board.

Nunnally, J. C., \& Bernstein, I. H. (1994). Psychometric theory. $3^{\text {rd }}$ ed. New York, NY: McGraw-Hill.

O'Connor, B. P. (2000). SPSS and SAS programs for determining the number of components: Using parallel analysis and Velicer's MAP test. Behavior Research Methods, Instruments \& Computers, 32, 396-402. Retrieved from https://people.ok.ubc.ca/brioconn/nfactors/rawpar.sps on 20 July 2011.

Parasuraman, R., \& Riley, V. (1997). Humans and automation: Use, misuse, disuse, abuse. International Journal of Aviation Psychology, 39(2), 230253.

Parasuraman, R., Sheridan, T. B., \& Wickens, C. D. (2000). A model for types and levels of human interaction with automation. IEEE Transactions on Systems, Man, and Cybernetics_Part A: Systems and Humans, 30(3), 286-298.

Pasztor, A. (2009). Captain's training faulted in air crash that killed 50. Wall Street Journal, 11 May.

Pololi, L., \& Price, J. (2000). Validation and use of an instrument to measure the learning environment as perceived by medical students. Teaching and Learning in Medicine, 12(4):201-237. Retrieved from http://www.informaworld.com/smpp/ on 10 May 2009.

Poprawa, S. (2011). Flight control automation. SA Flyer, December. Retrieved from http://www.saflyer.co.za/ on 20 January 2012.

Röttger, S., Bali, K., \& Manzey, D. (2009). Impact of automated decision aids on performance, operator behaviour and workload in a simulated supervisory control task. Ergonomics, 52(5), 512-523.

SACAA - see South African Civil Aviation Authority

Schaap, P. (2000). Die ontwikkeling van 'n psigometriese instrument om die leerbenaderings van volwassenes te bepaal. Unpublished DCom thesis, University of Pretoria, Pretoria, South Africa.

Schein, E. H. (2004). Organizational culture and leadership. $3^{\text {rd }}$ ed. San Francisco, CA: Jossey-Bass. 
Sexton, J.B., \& Klinect, J.R. (2001). The link between safety attitudes and observed performance in flight operations. In Proceedings of the Eleventh International Symposium on Aviation Psychology (pp. 7-13). Columbus, $\mathrm{OH}$ : Ohio State University.

Sherman, P. J. (1997). Aircrews' evaluations of flight deck automation training and use: Measuring and ameliorating threats to safety. Technical report. Austin, TX: University of Texas.

Singh, I. L., Sharma, H. O., \& Singh, A. L. (2005). Effect of training on workload in flight simulation task performance. Journal of the Indian Academy of Applied Psychology, 31(1-2), 83-91.

South African Airways (SAA). (2007). Flight Operations Manual (FOM). Johannesburg: Jeppesen Sanderson.

South African Civil Aviation Authority. (2011). Publications. Licencing and examinations. Retrieved from http://www.caa.co.za/ on 20 April 2011.

Tabachnick, B. G., \& Fidell, L. S. (2007). Using multivariate statistics. $5^{\text {th }}$ ed. Boston, MA: Allyn \& Bacon.

Tait, H., \& Entwistle, N. J. (1996). Identifying students at risk through ineffective study strategies. Higher Education, 31, 97-116.

Taylor, H. L., \& Emanuel, T. W. (2000). A civil aviation view of aircrew training. In H. F. O’Neil, \& D. H. Andrews (Eds.), Aircrew training and assessment (pp. 17-36). New York, NY: Erlbaum.

Telfer, R. A., \& Moore, P. J. (1997). Introduction. The roles of learning, instruction and the organisation in aviation training. In R. A. Telfer, \& P. J. Moore (Eds.), Aviation training: Learners, instruction and organisation (pp.103115). Aldershot, UK: Avebury Aviation.

Thorndike, E. L. (2007). Educational psychology. New York, NY: Read Country Books.

Uebersax, J. S. (2006). Likert scales: Dispelling the confusion. Statistical methods for rater agreement. Retrieved from http://johnuebersax.com/stat/likert.htm on 13 March 2010.

Velicer, W. F. (1976). Determining the number of components from the matrix of partial correlations. Psychometrika, 31:321-327. 
Vermeulen, L. P. (2009). Flight instructors' perceptions of pilot behaviour related to gender. South African Journal of Industrial Psychology, 35(1),128-136.

Walters, S. J. C. (2002). Study guide for Aviation Management 320. Aviation Safety Management. Pretoria: Department of Human Resources Management, University of Pretoria.

Wald, M. L. (2009). Clues point to speed issues in Air France crash. New York Times, 4 June.

Welman, J. C., \& Kruger, S. J. (1999). Research methodology for the business and administrative sciences. Halfway House, South Africa: Thomson International.

Wickens, C. D. (2000). Engineering psychology and human performance. $3^{\text {rd }}$ ed. New York, NY: Harper Collins.

Zimmerman, B. J., \& Risemberg, R. (1994). Investigating self-regulatory processes and perceptions of self-efficiency in writing by college students. Student motivation, cognition and learning: Essays in Honor of Wilbert J. McKeachie. Edited by P.R. Pintrich et al. New Jersey, NJ: Erlbaum, 239256.

Zwick, W. R., \& Velicer, W. F. (1986). Comparison of five rules for determining the number of components to retain. Psychological Bulletin, 99(3), 432442. 